I6 a 18 de outubro de 2019 - Campinas | Brasil

\title{
PERFIL DESCRITIVO DOS ESTUDANTES DE GRADUAÇÃO NA ÁREA DA SAÚDE DA UNICAMP NO ANO DE 2017 QUANTO A SEXUALIDADE, COMPORTAMENTO SEXUAL, ORIENTAÇÃO SEXUAL E IDENTIDADE DE GÊNERO
}

\author{
Isabella Juliano*, Amilton dos Santos Júnior.
}

\section{Resumo}

Comportamento sexual, sexualidade, orientação sexual e identidade de gênero são assuntos recorrentes e de extrema importância na atualidade. Sabe-se que é durante a juventude que muitos comportamentos sexuais têm início, tornando este momento repleto de novas experiências. Embora diversos aspectos sejam saudáveis e parte do desenvolvimento psicossocial, é um período com riscos, como gestações indesejadas e aquisição de doenças sexualmente transmissíveis. O presente trabalho teve por objetivo traçar um perfil descritivo dos estudantes de graduação da Área da Saúde da Universidade de Campinas (Unicamp), quanto a aspectos relacionados a sexualidade, comportamento sexual, orientação sexual e identidade de gênero. Foi possível que as análises preliminaresincluíssem também os alunos de todas as demais áreas do conhecimento da Unicamp, perfazendo um total de 6.912 questionários, aplicados entre 2017 e 2019 , acerca da iniciação sexual, vida sexual ativa e uso de métodos contraceptivos.

\section{Palavras-chave:}

Sexualidade, Gênero, Estudantes.

\section{Introdução}

Comportamento sexual, sexualidade, orientação sexual e identidade de gênero são assuntos recorrentes e de extrema importância na atualidade. Sabe-se que é durante a juventude que muitos comportamentos sexuais têm início, tornando este momento repleto de novas experiências. Embora diversos aspectos sejam saudáveis e parte do desenvolvimento psicossocial, é um período com riscos, como gestações indesejadas e aquisição de doenças sexualmente transmissíveis.

O presente trabalho, aprovado pelo Comitê de Ética em Pesquisa da Unicamp (parecer 1.903.287), teve por objetivo traçar um perfil descritivo dos estudantes de graduação da da Universidade de Campinas (Unicamp), referente ao ano de 2017, quanto a aspectos relacionados a sexualidade, comportamento sexual, orientação sexual e identidade de gênero. O recorte deste projeto previa a análise de dados de estudantes da área da saúde. Para os dados aqui apresentados, entretanto, foi possível analisar respostas de alunos do todas as áreas do conhecimento sobre iniciação sexual e se o estudante tem vida sexual ativa, além do uso ou não de preservativos e de pílula anticoncepcional. Os dados foram analisados a partir de questionários anônimos respondidos em sala de aula.

\section{Resultados e Discussão}

A amostra total inclui 6.912 estudantes, de todas as áreas do conhecimento, (47,9\% indivíduos do gênero feminino), com média de idade de 21,4 anos. Do total de participantes, $45,5 \%$ namoram ou têm algum relacionamento amoroso; $70,7 \%$ já tiveram relações sexuais e, destes, , 72,7\% mantinham vida sexual ativa, sendo $58,5 \%$ com parceiro(a) fixo. O uso de camisinha foi referido por $75,6 \%$ dos alunos com vida sexual ativa, e pílula anticoncepcional ou hormônio injetável, por $39,2 \%$, enquanto $7,7 \%$ destes estudantes referiam não usar nenhum método anticoncepcional e/ou de proteção.

Estudo realizado por Antunes em 2007 com estudantes universitários obteve porcentagem de indivíduos virgens de $46,77 \%$, ao passo que, na presente pesquisa, a porcentagem foi de $29,28 \%$. Os resultados de Antunes apresentaram $5,42 \%$ de indivíduos que não fazem uso de qualquer método contraceptivo, porcentagem inferior à obtida na presente pesquisa $(7,65 \%)$.

Apesar de tratar-se de dados ainda preliminares, já é possível perceber determinados padrões de comportamento dos estudantes. Dado importante é a elevada porcentagem de indivíduos que não fazem uso de nenhum método anticoncepcional ou de proteção $(7,7 \%)$, principalmente levando em consideração que uma porcentagem elevada da amostra atualmente tem vida sexual ativa. Tais dados apontam a necessidade de campanhas de ensino e conscientização sobre uso de preservativos e outros métodos contraceptivos.

Na próxima etapa da presente pesquisa serão analisados os perfis dos estudantes por áreas específicas do conhecimento, incluindo a dos cursos de saúde. Além disso, serão testadas possíveis associações dos padrões apresentados com outras dimensões de suas vidas, incluindo identidade de gênero e orientação sexual. Com o aumento da análise da amostra para além dos cursos da Área da Saúde, o banco de dados está em fase final de revisão.

\section{Conclusões}

Embora cerca de um terço dos alunos ainda não tenha iniciado a vida sexual, dentre os que já iniciaram, há um número considerável de estudantes que mantém vida sexual ativa e que não utiliza métodos de proteção de gravidez indesejada e de doenças sexualmente transmissíveis, o que reforça a importância da adoção de medidas específicas de orientação e prevenção.

\section{Agradecimentos}

O projeto de pesquisa principal conta com os seguintes apoios financeiros $\mathrm{e}$ institucionais, pelos quais agradecemos: FAPESP (Auxílio Pesquisa Regular Processo 2017/01842-6), FAEPEX, PIBIC-EM, CAPES, CNPq, Serviço de Apoio ao Estudante (SAE), Pró-Reitorias de Graduação (PRG) e de Pesquisa (PRP) da Unicamp.

\section{Referências}

